\title{
Initial results of Mars2020: characterization of the geological context of the future samples of Mars Sample return
}

\author{
PROF. CATHY QUANTIN-NATAF ${ }^{1}$, KEN FARLEY ${ }^{2}$, \\ KATHRYN M. STACK ${ }^{3}$, KENNETH H. WILLIFORD ${ }^{3}$, \\ NICOLAS MANGOLD ${ }^{4}$ AND ADRIAN J. BROWN ${ }^{5}$ \\ ${ }^{1}$ Université Lyon1 \\ ${ }^{2}$ California Institute of Technology \\ ${ }^{3}$ JPL/Caltech \\ ${ }^{4}$ LPG UMR 6112 CNRS/Université de Nantes \\ ${ }^{5}$ Plancius Research \\ Presenting Author: cathy.quantin@univ-lyon1.fr
}

Initial results of Mars2020: characterization of the geological context of the future samples of Mars Sample return

Quantin-Nataf' K.A. Farley, K. M. Stack, K.H. Williford, N. Mangold, A. Brown and Mars2020 science team

On February 18, 2021, NASA's Mars 2020 Perseverance rover will land in Jezero crater, a $40 \mathrm{~km}$ crater located on the margin of the Isidis basin on Mars where the crust of Mars in uniquely exposed [e.g.1]. The Mars 2020 mission is the first step of a conceptual joint NASA-ESA Mars sample return campaign, as Perseverance has the capability of collecting and caching about 35 samples [2]. The scientific payload is dedicated to the search for biosignatures and characterization of ancient geological environments using imaging, infrared spectroscopy, Raman spectroscopy, laser-induced breakdown spectroscopy, and X-ray fluorescence spectroscopy...[2]. A key new feature is the ability to co-register color, texture, chemistry, and mineralogy maps both at the outcrop scale and the microscopic scale.

Jezero is a Noachian crater with an inlet valley leading to a delta implying that the crater was a lake early in the planet's history [3]. Several geological units are observed within the Jezero crater landing ellipse: 1) a cratered dark floor unit interpreted either as a late fluvial unit or as a volcanic unit [3], 2) a regional widespread olivine-carbonate-phyllosilicate bearing unit exposed in Jezero in erosional windows below the dark floor unit $[4,5], 3)$ a deltaic complex that has experienced extensive erosion [6;7] and 4) a marginal carbonate bearing unit, possibly stromatolite bearing and related to distal lacustrine or fluvial deposits [8].

We will present results of the first four months of the mission with special attention to the team's evolving understanding of the geological setting from which samples will be acquired.

\section{References}

[1] Mustard et al., 2009, J.G.R. ;[2] Farley, K. A. et al., 2020. Space Sci. Rev; [3] Stack K. M. et al., 2020 Space Science Rev. ; [4] Mandon et al.,2020, Icarus ; [5] Brown et al., [6] Mangold et al., 2020, Astrobiology ; [7] Goudge et al., EPSL, 2017 ; [8] Horgan, B. et al., 2020 Icarus. 